\title{
Central blockade of NLRP3 reduces blood pressure via regulating inflammation microenvironment and neurohormonal excitation in salt-induced prehypertensive rats
}

Mo-Lin Wang ${ }^{1,2+}$, Yu-Ming Kang ${ }^{1+}$, Xiao-Guang Li ${ }^{3}$, Qing Su', Hong-Bao Li', Kai-Li Liu', Li-Yan Fu', Roland Osei Saahene ${ }^{2}$, Ying Li ${ }^{1}$, Hong Tan ${ }^{1,4}$ and Xiao-Jing $\mathrm{Yu}^{1 *}$

\begin{abstract}
Background: Inflammation has been implicated in the development of cardiovascular disease. We determined whether nod-like receptor with pyrin domain containing 3 (NLRP3) involved in the process of prehypertension, central blockade of NLRP3 decreased inflammation reaction, regulated neurohormonal excitation, and delayed the progression of prehypertension.

Methods: Prehypertensive rats were induced by $8 \%$ salt diet. The rats on high-salt diet for 1 month were administered a specific NLRP3 blocker in the hypothalamic paraventricular nucleus (PVN) for 4 weeks. ELISA, western blotting, immunohistochemistry, and flow cytometry were used to measure NLRP3 cascade proteins, pro-inflammation cytokines (PICs), chemokine ligand 2 (CCL2), C-X-C chemokine receptor type 3 (CXCR3), vascular cell adhesion molecule 1 (VCAM-1), neurotransmitters, and leukocytes count detection, respectively.

Results: NLRP3 expression in PVN was increased significantly in prehypertensive rats, accompanied by increased number of microglia, $\mathrm{CD}^{+}{ }^{+}, \mathrm{CD}^{+} \mathrm{T}$ cell, and $\mathrm{CD} 8^{+}$microglia. Expressions of PICS, CCL2, CXCR3, and VCAM-1 significantly increased. The balance between $67-\mathrm{kDa}$ isoform of glutamate decarboxylase (GAD67) and tyrosine hydroxylase (TH) was damaged. Plasma norepinephrine (NE) in prehypertensive rats was increased and gamma-aminobutyric acid (GABA) was reduced. NLRP3 blockade significantly decreased blood pressure, reduced PICs, CCL2, VCAM-1 expression in PVN, and restored neurotransmitters. Blood pressure and inflammatory markers were upregulated after termination of central blockage NLRP3.
\end{abstract}

Conclusions: Salt-induced prehypertension is partly due to the role of NLRP3 in PVN. Blockade of brain NLRP3 attenuates prehypertensive response, possibly via downregulating the cascade reaction triggered by inflammation and restoring the balance of neurotransmitters.

Keywords: NLRP3, Hypothalamic paraventricular nucleus, Inflammation, Neurotransmitters, Microglia, Hypertension

\footnotetext{
* Correspondence: yuxiaojing@mail.xjtu.edu.cn

${ }^{\dagger}$ Equal contributors

'Department of Physiology and Pathophysiology, Xi'an Jiaotong University School of Basic Medical Sciences, Key Laboratory of Environment and Genes Related to Diseases (Xi'an Jiaotong University), Ministry of Education, Xi'an 710061, China

Full list of author information is available at the end of the article
} 


\section{Background}

Recent evidences have associated hypertension with a chronic low-grade systemic inflammation [1].The most susceptible among all organs to increased blood pressure is the brain [2]. The hypothalamic paraventricular nucleus (PVN) plays a key role in endocrine-autonomic control by regulating baroreflex function, sympathetic output, and salt appetite [3]. Furthermore, growing body of evidence have demonstrated that increased pro-inflammatory cytokines (PICs) within PVN play an important role in the progression of hypertension $[4,5]$. Researches described that hypertension is associated with increased Toll-like receptor 4 (TLR4) expression in the PVN of essential and angiotensin II induced hypertensive rats [6, 7]. However, the role of intracellular NOD like receptors, such as pyrin domain containing 3 (NLRP3) in hypertension remains unknown. Then, in this study, we analyze the role of NLRP3, PICs, chemokine ligand 2 (CCL2), C-X-C chemokine receptor type 3 (CXCR3), vascular cell adhesion molecule 1 (VCAM-1), and neurohormone level in the development of prehypertension.

Upon activation, NLRP3 inflammasome is formed when NLRP3 recruits the adapter protein apoptosisassociated speck-like protein (ASC) and pro-cysteine aspartic acid protease-1 (pro-caspase-1). The NLRP3 inflammasome is assembled and matured under different exogenous and endogenous activators, resulting in the production of interleukin-1 beta (IL-1 $\beta$ ) and interleukin-18 (IL-18) [8]. IL-1 $\beta$ is a multifunctional cytokine which contributes to chronic inflammation and induces strong inflammatory response during cardiovascular diseases [9-12]. Several physiological and endocrine adjustments induced by immune activation are mediated and performed by IL-1 $\beta$ in the brain [13]. Recent study also suggests that blood pressure and serum norepinephrine level is increased when IL-1 $\beta$ was injected into the brain [14].

The state of inflammation and immune activation perpetuated in hypertension may affect severity and progression of tissue and organ injury. An excessive inflammatory response is well-recognized in determining hypertension process and hypertensive brain damage [15]. Activation of monocytes correlates with hypertension in the periphery and increased plasma pro-inflammatory cytokines [16-18]. The activation of brain-resident astrocytes, microglia, and upregulation of adhesion molecules expression on brain endothelial cells occur as a result of increased blood pressure $[19,20]$. The expression of ICAM- 1 and VCAM- 1 by endothelial cells further promote inflammation [21]. CCL2 is also called monocyte-chemotactic protein (MCP-1), which was upregulated in the kidneys of deoxycorticosterone acetate (DOCA) salt-hypertensive animals [22]. Recent studies have shown that chemokine CXCR3 and its corresponding chemokine ligands, CXCL9, CXCL10, and CXCL11, are expressed in central nervous system diseases [23-25]. CXCR3 is a well-known tissue-homing chemokine for $\mathrm{T}$ cells, which is highly expressed in the circulation of hypertensive patients. $\mathrm{CD}^{+}$and $\mathrm{CD}^{+} \mathrm{T}$ cells in hypertensive patients have increased renal infiltration than control group [26].

Accordingly, we hypothesized that NLRP3 activation was associated with hypertension, upregulation of proinflammatory cytokines IL-1 $\beta$, interleukin-6 (IL-6), tumor necrosis factor- $\alpha$ (TNF- $\alpha$ ); adhesion molecule VCAM-1, chemokine CCL2, CXCR3 in PVN, and microglial activation, contribute to the inflammatory reaction with amplification, which resulted in an imbalance of excitatory and inhibitory neurotransmitters, increase of sympathetic excitability and elevated blood pressure. Furthermore, we postulated that blockade of NLRP3 in PVN could have important functional consequences and lead to an associated decrease in hypertension by regulating inflammation microenvironment and neurotransmitters. This research will reveal a potential new therapeutic target for the treatment of hypertension.

\section{Methods}

\section{Experimental animals}

The experimental animals were made up of male Sprague-Dawley (SD) rats (250-270 g). The rats were kept and maintained at temperatures of $\left(20-23{ }^{\circ} \mathrm{C}\right)$ under controlled $12 \mathrm{~h} / 12 \mathrm{~h}$ dark/light cycle. The experimental rules and regulations in accordance with the National Institutes of Health Guide for the Care and Use of Laboratory Animals were duly followed. The approval for our study was obtained from the Xi'an Jiaotong University Committee for Animal Research.

\section{General experimental protocol}

$0.3 \% \mathrm{NaCl}$ and $8 \% \mathrm{NaCl}$ were administered to normalsalt (NS) group and the high-salt (HS) group over a period of 3 months, respectively. The rats were divided into 10 groups: (i) normal salt 2 months (NS2), (ii) high salt 2 months (HS2), (iii) normal salt 3 months (NS3), (iv) high salt 3 months (HS3), (v) NS + Vehicle, (vi) NS + MCC950, (vii) HS + Vehicle, (viii) HS + MCC950, (ix) NS + MCC950', (x) HS + MCC950'.

After high-salt diet for 4 weeks, bilateral cannulae were implanted into the PVN of (v), (vi), (vii), (viii), (ix), and (x) groups rats for infusion of MCC950 (15 $\mu \mathrm{g} / \mathrm{h}$, Medchem Express), a specific NLRP3 blocker, or vehicle (artificial cerebrospinal fluid, aCSF). The dose applied for MCC950 was assessed from a study in rats with doses of 3,15 , and $65 \mu \mathrm{g} / \mathrm{h}[27,28]$. The highest dose caused mortality while the $15 \mu \mathrm{g} / \mathrm{h}$ produced optimal response but the low dose recorded an incomplete inhibition. After 4 weeks of drug intervention, at the end 
of 8 weeks rats of (v), (vi), (vii), and (viii) groups were administered an anesthesia of ketamine $(80 \mathrm{mg} / \mathrm{kg})$ and xylazine $(10 \mathrm{mg} / \mathrm{kg}$ ) mixture (ip); following this, the brains, hearts, aortas, and peripheral blood were removed and immediately frozen on dry ice. But (ix) and (x) groups were kept, and the rats were fed with highsalt diet for another 1 month without treatment until the end of the experiment.

\section{The intra-paraventricular nucleus cannula application for chronic infusion}

A 28-day mini osmotic pump (infusion rate $0.25 \mu \mathrm{l} / \mathrm{h}$; Alzet, model 2004, Durect Corporation, Cupertino, CA, USA) was through a catheter tube connected to the infusion cannula to deliver MCC950 or vehicle in the PVN, as described previously [29].

\section{Blood pressure measurements}

The noninvasive computerized tail-cuff system (NIBP, AD Instruments, Australia) was applied for measuring blood pressure of the tail artery in conscious rats, as described previously in our report [30]. The mean blood pressure of all rats were determined and recorded per week.

\section{Hematoxylin and eosin staining}

$5 \mu \mathrm{m}$ pathology slices from the brain, aorta, and heart were prepared to discern morphology by staining with hematoxylin and eosin (H\&E).

\section{Immunohistochemistry staining}

The following antibodies were immunohistochemically determined: NLRP3 (1:200, Santa Cruz, CA, USA), IL-1 $\beta$ (1:200, Santa Cruz, CA, USA), ASC (1:100, Santa Cruz, CA, USA), pro-casp-1 (1:100, Santa Cruz, CA, USA), $\mathrm{CD}^{+}$(1:200, Santa Cruz, CA, USA), Iba-1 (1:200, Santa Cruz, CA, USA), TH (1:200, Santa Cruz, CA, USA), and GAD67 (1:200, Santa Cruz, CA, USA). The detailed immunostaining protocol performed was the same as in our previous research $[29,31]$. The Image-Pro Plus software was applied in the analysis of the integral optical density and fluorescence intensity.

\section{Isolation of peripheral blood mononuclear cells (PBMCs)} $4 \mathrm{ml}$ of Ficoll-Hypaque were added to $50 \mathrm{U} / \mathrm{ml}$ heparinized venous bloods and centrifuged at $400 \mathrm{~g}$ for $30 \mathrm{~min}$ at room temperature. PBMC interface layer was washed in phosphate buffer saline (PBS) twice and was centrifuged for $10 \mathrm{~min}$ at $300 \mathrm{~g}$. RPMI medium supplemented with fetal calf serum was used to resuspend cells to a final concentration of $1 \times 10^{6}$ monocytes $/ \mathrm{ml}$ [32] .

\section{Western blotting}

The brain was sectioned serially in $300 \mu \mathrm{m}$ increments from the bregma to lambda, both sides of the PVN tissues were isolated by the use of a punch-out technique with a cryostat [33,34], and the PVN tissue was stored at $-80{ }^{\circ} \mathrm{C}$ until use. Western blotting analysis was performed in the same manner as previously described [6]. The protein levels were determined from tissue homogenate obtained from the PVN for the following antibodies: NLRP3 (1:2000, Santa Cruz, CA, USA), ASC (1:500, Santa Cruz, CA, USA), pro-caspase-1 (1:2000, Abcam, MA, USA), IL-1 $\beta$ (1:500, Santa Cruz, CA, USA), CXCR3 (1:2000, Abcam, MA, USA), VCAM1, ICAM-1 (1:2000, Abcam, MA, USA), and CCL2 (1: 2000, Santa Cruz, CA, USA), Iba-1 (1:500, Santa Cruz, CA, USA). The $\beta$-actin antibody was used as an internal standard, and band densities were analyzed with $\mathrm{NIH}$ ImageJ software.

\section{Flow cytometric analysis of leukocyte in PBMCs}

PBMCs were transferred to a tube and stained with an antibody cocktail consisting of CD3, CD4, and CD8 (BD Bioscience, USA) diluted in PBS. Samples were then analyzed by flow cytometry using a FACS Calibur TM cytometer (BD Biosciences, San Jose, CA, USA).

\section{Cytokines measure}

Commercially available rat ELISA kits were used to quantify tissue TNF- $\alpha$, IL- 6 , and plasma norepinephrine (Invitrogen Corporation, CA, USA) following the manufacturer's instructional manual.

\section{Data analysis}

The data were recorded as mean \pm SEM. Data were analyzed between two groups using the Student's $t$ test. For experiments that involved multiple groups, data analyses were conducted by either a one-way or two-way ANOVA followed by a post hoc Bonferroni test. A probability value of $P<0.05$ was inferred to be statistically significant.

\section{Results}

The role of NLRP3 on blood pressure in salt-induced prehypertensive rats

The initial blood pressure baseline levels were similar. By the fourth week of high-salt diet, the blood pressure of high-salt diet rats had gradually increased. The MAP of high-salt group increased significantly after 8 weeks compared with NS groups (Fig. 1a). Chronic PVN infusion of MCC950, a specific NLRP3 antagonist for 4 weeks of high-salt diet, blood pressure of $\mathrm{HS}+$ MCC950 group was no longer increased; however, the MAP of HS + MCC950' group was increased compared with the control group, after the central occlusion of 

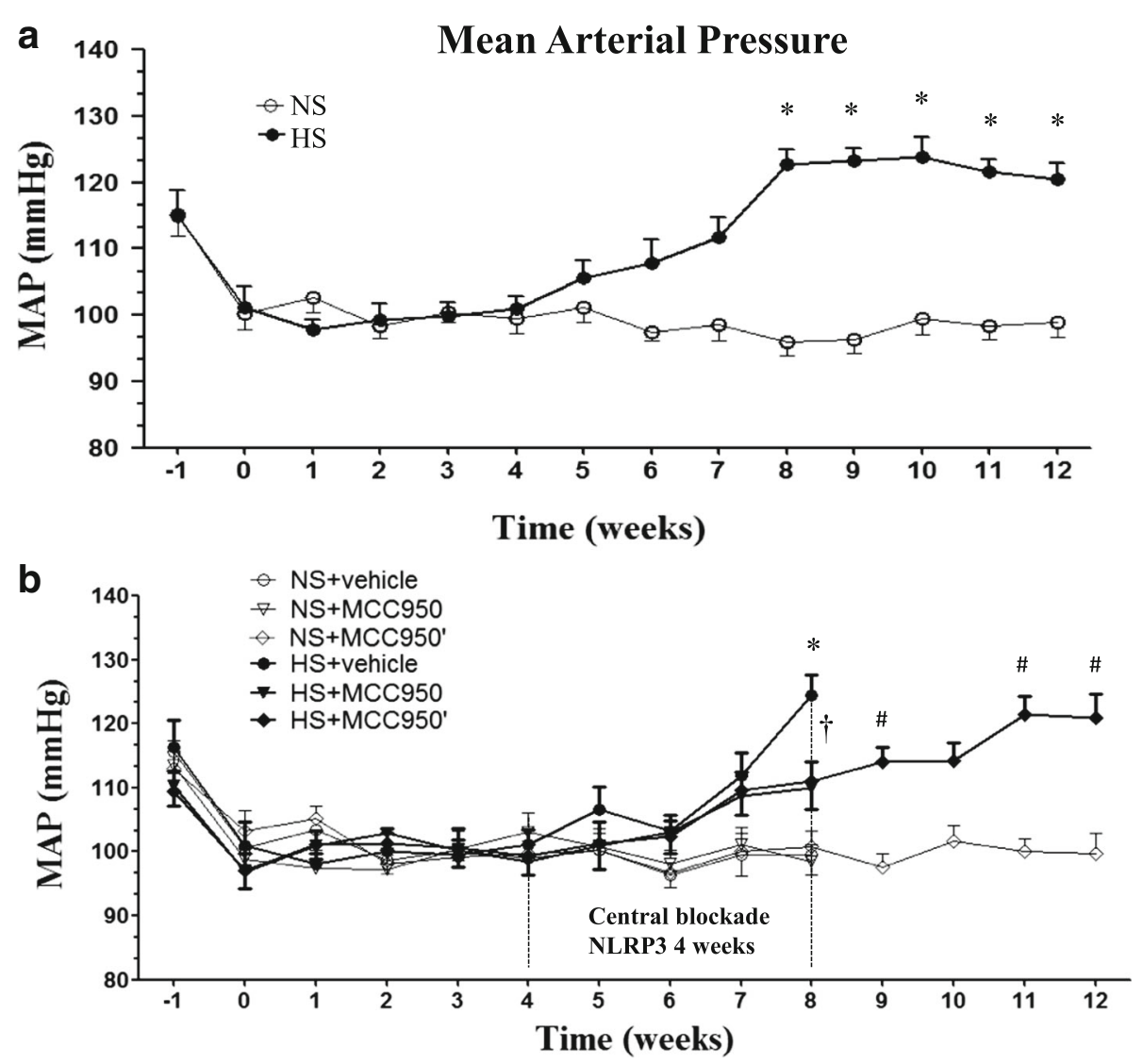

Fig. 1 Effects of NLRP3 on MAP in salt-induced prehypertension rats. a The blood pressure of the high-salt group increased gradually after 2 months of high-salt diet in comparison with control group. b Compared with HS + vehicle rats, chronic PVN infusion of MCC950 a specificity NLRP3 antagonist for 4 weeks attenuated hypertension. Blood pressure continued to arose after 4 weeks of discontinuation treatment. Values are expressed as means \pm SEM, $n=6-8 .{ }^{*} P<0.05$, NS vs HS, or NS + vehicle vs HS + vehicle, $+P<0.05, \mathrm{HS}+\mathrm{MCC} 950$ vs HS + vehicle, \#P<0.05, HS + MCC950' vs NS + MCC950'

NLRP3 was stopped and the high salt feeding for another 4 weeks (Fig. 1b).

The expression of NLRP3/ASC/IL-1 $\beta$ in the PVN of high-salt diet rats by the second month

In this study, we found that NLRP3, ASC, and IL-1 $\beta$ expressions in the PVN of high-salt diet increased significantly by the second month, with a corresponding increase in the blood pressure. Most interestingly, the NLRP3 pathway proteins expression had no difference between the high-salt diet for 2 and 3 months (Fig. 2).

The expression of NLRP3 in the heart, aorta, and plasma pro-inflammatory cytokines in HS group by the second month

Our study demonstrated that HS group had shown significantly increased NLRP3 in the heart and aorta since the second month, as shown in Fig. 3a-c. ELISA results showed that plasma TNF- $\alpha$ and IL- 6 in the HS groups by the second month were higher than those in the NS rats (Fig. 3e, f).
Morphologically, we observed that the cardiac myocytes nucleus enlarged in the HS model since the third month, which indicated early myocardial hypertrophy (Fig. 3d).

The number of microglia was increased in the cortex and hippocampus of rats with high salt for 2 and 3 months Immunohistochemistry and western blotting showed that the number of microglia in hippocampus and cortex of the HS group was higher than that of the control group (Fig. 4).

\section{$\mathrm{CD}^{+}$and $\mathrm{CD} 8^{+} \mathrm{T}$ cells in PBMCs and $\mathrm{CD} 8^{+}$microglias/} macrophages in the brain were increased in of high-salt diet rats since the third month

We performed flow cytometric analysis to determine leukocyte numbers in PBMCs. Compared to NS rats, the number of T cell in PBMCs was elevated in HS rats. Further analysis of $\mathrm{T}$ cell subsets showed that the populations of $\mathrm{CD} 4^{+}$and $\mathrm{CD}^{+} \mathrm{T}$ cells increased significantly (Fig. 5). In peripheral circulation, the expression of $\mathrm{CD}^{+}{ }^{+}$and $\mathrm{CD} 8^{+} \mathrm{T}$ 


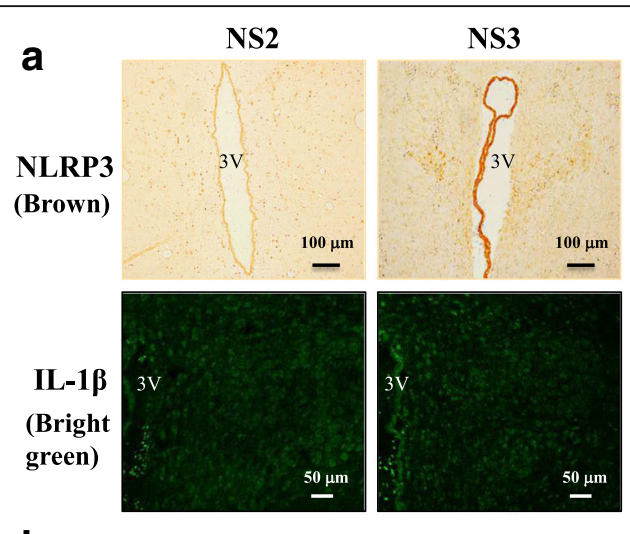

b

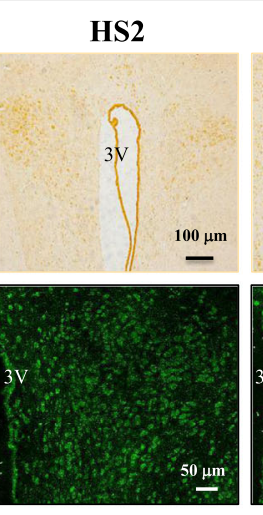

HS3

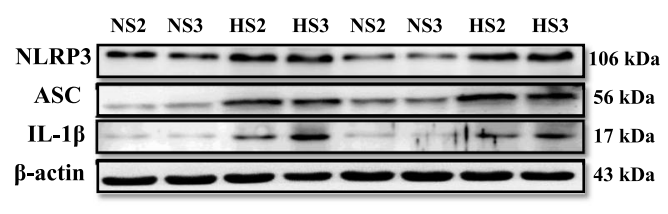

C

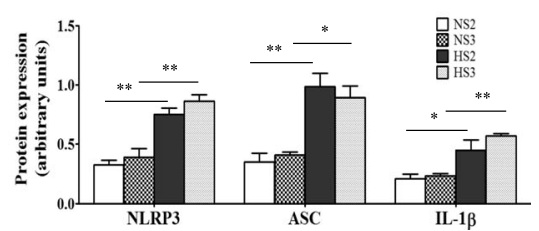

Fig. 2 The expression of NLRP3 pathway protein in PVN. a A representative immunohistochemistry image of NLRP3, scale bar $100 \mu$ m, immunofluorescence image of IL-1 $\beta$, scale bar $50 \mu \mathrm{m}$, showing the changes of NLRP3, IL-1 $\beta$ in the high-salt diet rats from 2 to 3 months. $\mathbf{b}$ A representative immunoblot of NLRP3/ASC/IL-1 $\beta$. c Analysis of NLRP3 pathway expression in various groups; $n=3$. Values are expressed as means $\pm \mathrm{SEM}$. ${ }^{*} P<0.05,{ }^{*} P<0.001$, vs control (NS), $3 \mathrm{~V}$, third ventricle

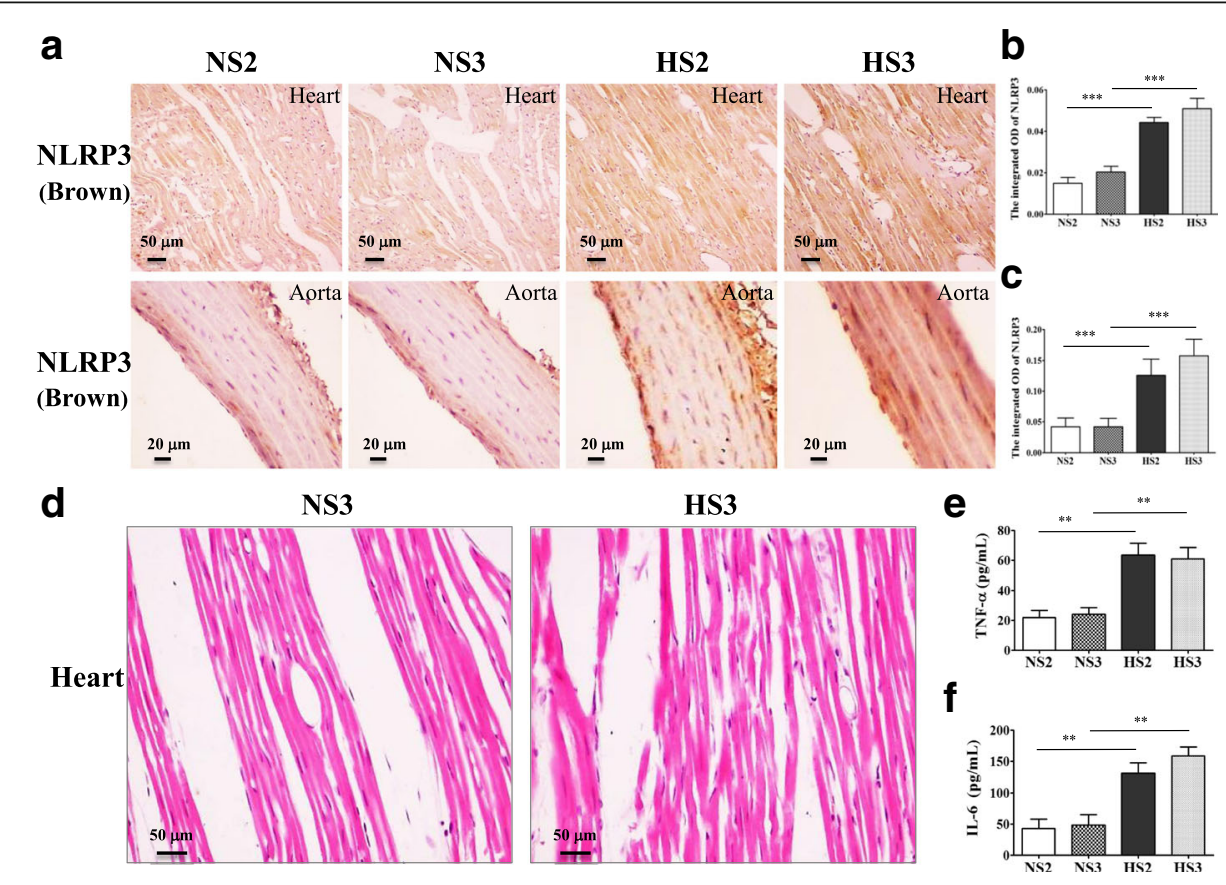

Fig. 3 a A representative immunohistochemistry image of NLRP3 in the heart and aorta, scale bar 50 and $20 \mu m$, showing the changes of NLRP3 in the high-salt diet rats from 2 to 3 months. $\mathbf{b}$ Analysis integrated OD of NLRP3 in various heart tissue groups, $n=6-8$. c Analysis integrated OD of NLRP3 in various aorta tissue groups, $n=6-8$. d The tissue sections of the left ventricles were stained by HE staining, scale bar $50 \mu \mathrm{m}$. e ELISA detection plasma TNF-a expression in the various groups, $n=6-8$. $\mathbf{f}$ ELISA detection plasma IL-6 expression in the various groups, $n=6-8$.Values are expressed as means \pm SEM. ${ }^{* *} P<0.001,{ }^{* * *} P<0.0001$ vs control (NS) 

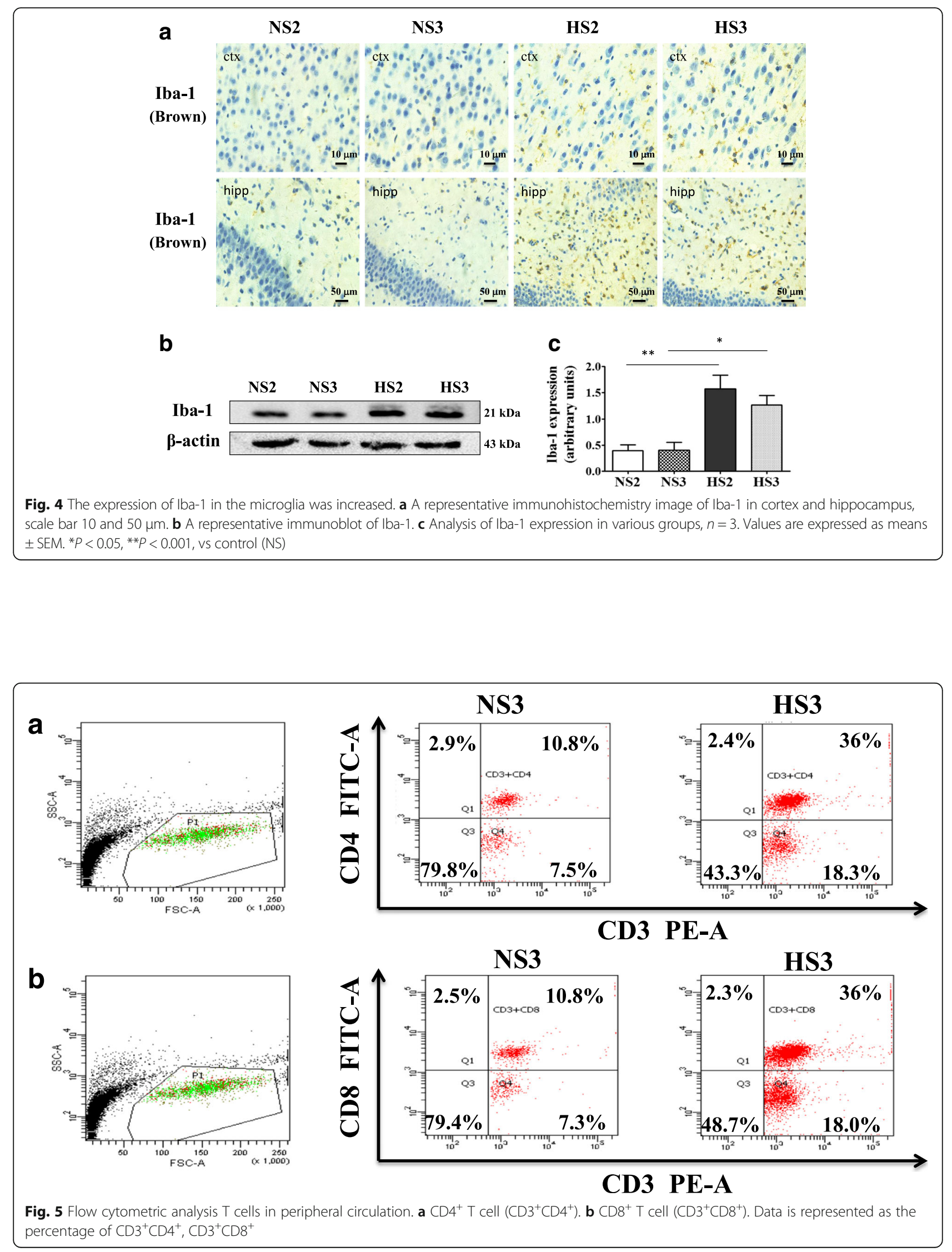
cells increased, and expression of CXCR3 in PVN was upregulated. Therefore, we sought to find infiltrating $\mathrm{T}$ cells in the brain parenchyma. We did not find infiltrating $\mathrm{T}$ cells in the brain, but we found microglias/macrophages expressing CD8 molecules in the cortex, corpus callosum, hippocampus, choroid plexus, as well as neurons expressing CD8 molecules in hippocampus and PVN. Jander has previously reported the expression of $\mathrm{CD}^{+}$macrophages in the central nervous system [35, 36] (Fig. 6).

\section{Blockade NLRP3 suppression of ASC/pro-caspase-1/IL-1 $\beta$ expression in PVN of high-salt diet rats}

To determine whether suppression of NLRP3 in PVN attenuates inflammation response, we examined the protein level of NLRP3 pathway in PVN. Chronic PVN infusion of MCC950 significantly decreased ASC, pro-caspase- 1 , and IL-1 $\beta$ expression in high-salt diet rats (Fig. 7a, b). However, when the drug intervention was stopped and continued with high-salt feeding for a month, we observed that the ASC and IL-1 $\beta$ of HS + MCC950' group was significantly increased in PVN than those of control group (Fig. 7c-e).

Central blockade NLRP3 inhibited VCAM-1, CXCR3, CCL2, and PICs expression in the PVN of high-salt diet rats

Western blotting revealed that several inflammatory markers adhesion molecule VCAM-1, chemokine CXCR3, and CCL2 were increased in prehypertensive rats compared to NS rats. Central blockade NLRP3 attenuated VCAM-1, CXCR3, and CCL2 expression (Fig. 8a, b). Termination of intervention and continued high-salt feeding for a month, led to significant upregulation VCAM-1,CXCR3, and CCL2 in the MCC950' treatment group, as shown in Fig. 8c, d. ELISA analysis showed that HS + vehicle group had significant increase in IL- 6 and TNF- $\alpha$ expression in the PVN compared with NS + vehicle group. The upregulation of TNF- $\alpha$ and IL- 6 were significantly attenuated by central blockade NLRP3 (Fig. 8e, f).

\section{Central blockade NLRP3 regulates PVN excitatory and inhibitory neurotransmitters and plasma norepinephrine and GABA}

Compared with control groups, hypertensive rats had higher expression of $\mathrm{TH}$ and lower expression of GAD67 in the PVN. Chronic infusion of MCC950 into the PVN for 4 weeks decreased the expression of $\mathrm{TH}$ and increased GAD67 expression in prehypertensive rats induced by salt. Plasma NE in prehypertensive rats was increased and GABA was reduced; interestingly, central blockade of NLRP3 significantly decreased plasma NE and upregulated GABA levels in PVN (Fig. 9).

\section{Discussion}

In this study, the role of NLRP3 expression in the PVN of salt-induced prehypertension was defined. The novel

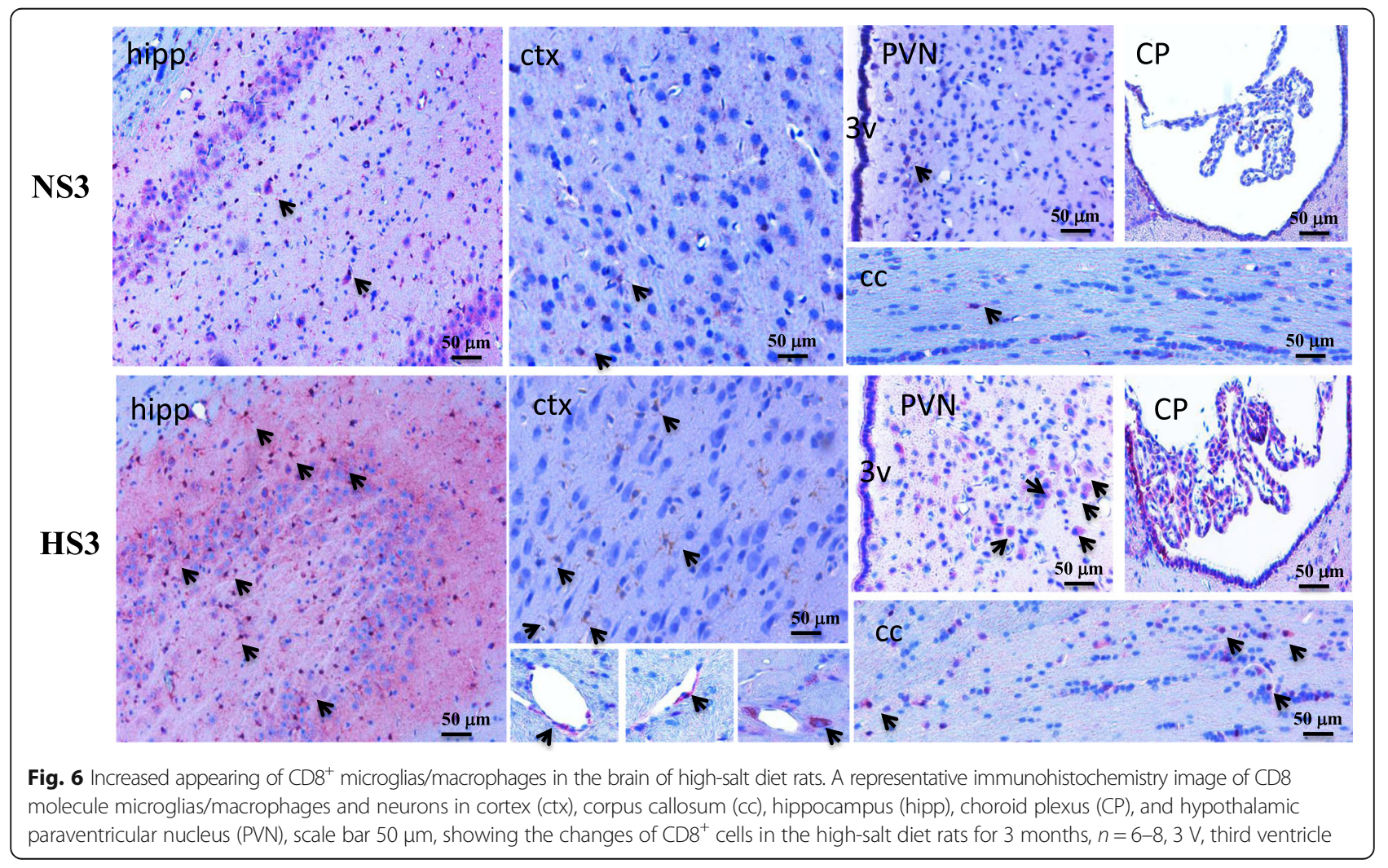




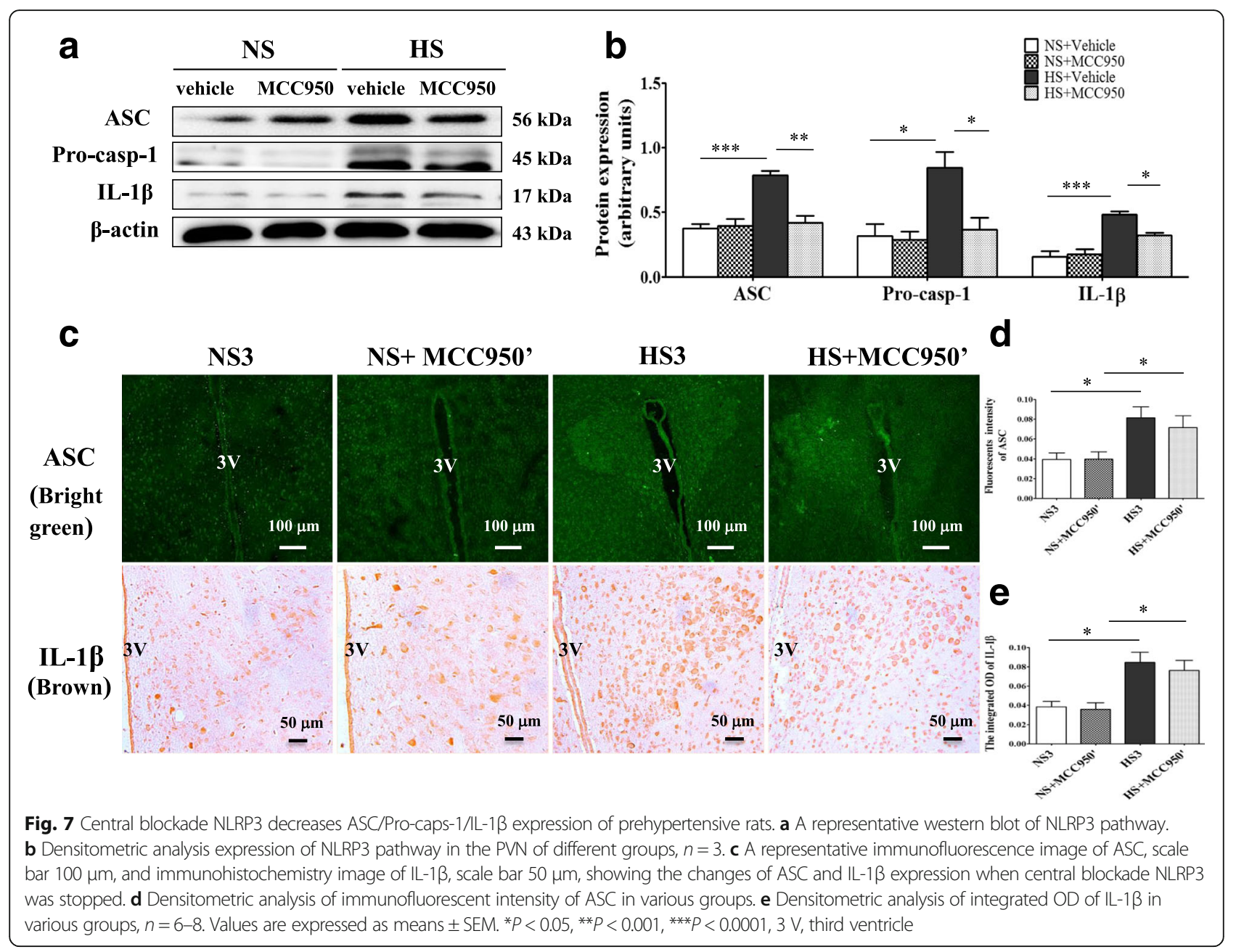

outcomes of this present research are the following: (1) NLRP3 expression in the PVN of high salt was increased with corresponding elevated blood pressure, (2) NLRP3 activation in the PVN was accompanied by high expression of PICs, adhesion molecule VCAM-1, chemokine CCL2 and CXCR3, as well as breaking the balances of neurotransmitters in the PVN, (3) microglial activation, $\mathrm{CD} 8^{+}$microglias/ macrophages were increased in brain parenchyma of prehypertensive rats, (4) central blockade of NLRP3 in the PVN attenuated prehypertension resulting from regulating the inflammation microenvironment and restoring the balances of neurotransmitters in PVN, (5) NLRP3 was not only upregulated in the PVN, but also highly expressed in the peripheral tissue, heart and aorta.

PVN in the brain is notable as an important endocrineautonomic control area which contributes to sympathetic regulation of blood pressure and body fluid homeostasis [37]. The sympathetic outflow from the PVN depends on the balance of different kinds of neurotransmitter activities. Increasingly evidences demonstrated that the increased sympathetic activation is due to an increase in excitatory adrenergic and glutamatergic activities and a decrease in GABAergic activity in the PVN [38]. In chronic sterile inflammation, inflammatory responses are caused and maintained by the NLRP3 inflammasome [39], which activation of pro-caspase- 1 and IL- $1 \beta, \mathrm{IL}-1 \beta$ is recognized as the main activator of inflammation, which serves as a mediator to trigger the cascade release of other cytokines. Reports have demonstrated that various PICs such as TNF- $\alpha$, IL-1 $\beta$, and IL- 6 play a vital role in the development of hypertension [31, 40-42]. Tissue cells synthesize inflammatory mediators and chemokine in response to injury and stress, to recruit inflammatory cells. Positive feedback loops result as inflammatory cells perpetuate the release of cytokines and express adhesion molecules. Studies have shown that adhesion molecules ICAM-1, VCAM1 , immune cells, chemokine CCL2, and CXCR3 are key factors in human hypertension [21, 22, 26]; these series of events results in the progression of hypertension.

In this study, we provide the evidence that NLRP3 plays a key role in prehypertension induced by salt. Our study demonstrated that HS rats recorded a significant increase 


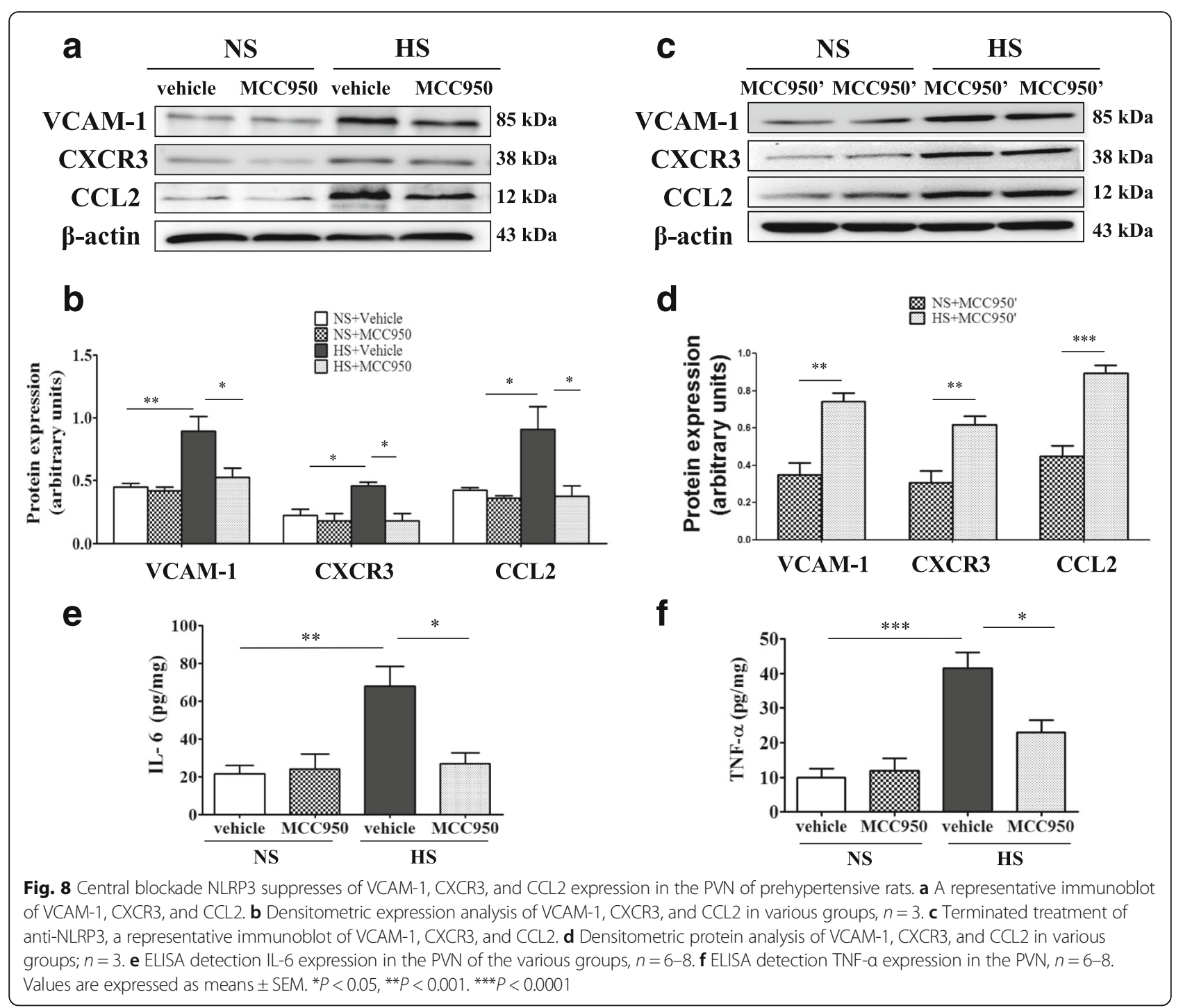

in MAP in comparison with NS group by the 2 months of high-salt diet, and the changes were paralleled with NLRP3 increased expression in HS group. HS group feed with high salt for 2 months had significant increase in NLRP3 not only in the PVN but also in the heart and aorta peripheral tissues, as well as upregulated plasma IL- 6 and TNF- $\alpha$.We also found that VCAM-1, chemokine CCL2, and CXCR3 in the PVN were increased since the second month of highsalt diet. During inflammatory responses, chemokine classically mediate, migrate, and traffic cells to sites of inflammation [43]. Arterial hypertension affects bone marrow hematopoietic niche directly by increased levels of monocytes and neutrophils in the circulation [44]. In fact, previous studies showed that the blood and brain of naive SHR expressed increased monocyte and neutrophil counts [45-47]. Our data illustrated that the number of microglia in the cortex and hippocampus and total T cells in the peripheral circulation in HS rats were increased compared to
NS rats, and further analysis of the immune cell subsets revealed that the populations of $\mathrm{CD}^{+}$and $\mathrm{CD} 8^{+} \mathrm{T}$ cells were increased significantly.

We try to find the infiltration of T cells in the brain parenchyma without success, but we found the number of $\mathrm{CD}^{+}$microglias/macrophages in the brain increased. Both CD4 and CD8 antigens were originally described as antigen coreceptors on helper and cytotoxic/suppressor $\mathrm{T}$ lymphocytes, respectively. However, Jander et al. described a population of activated central nervous system (CNS) macrophages characterized by the expression of the CD8 molecule $[35,36]$.

Our next step sought to determine whether the antiNLRP3 therapy could decrease cascade reaction of inflammation, regulate neurotransmitters, and counteract hypertension. We found that blockade NLRP3 therapy markedly reversed hypertension, in consistent with the results reported by Krishnan [48], as well as significantly 


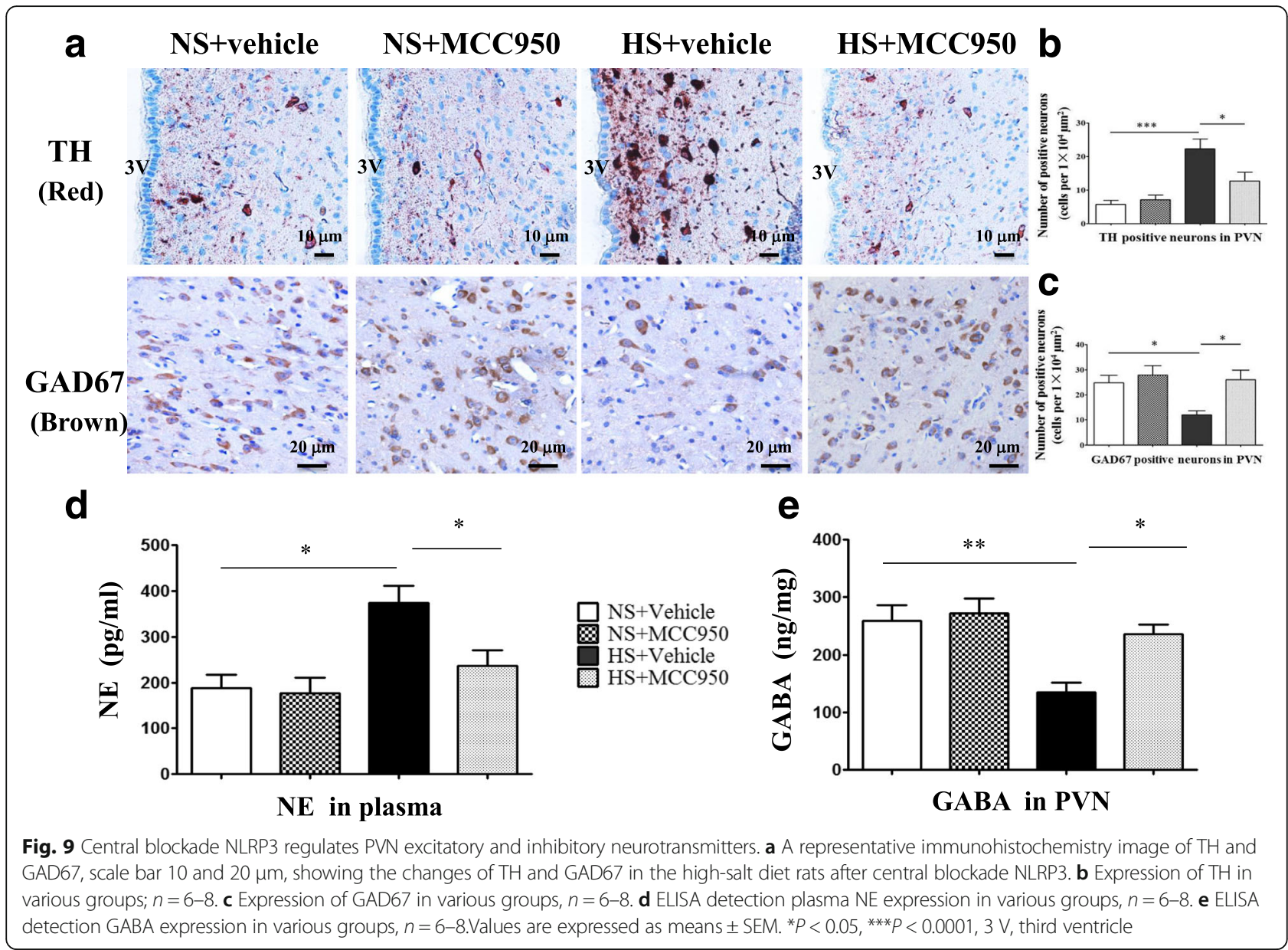

reduced NLRP3 pathway protein expression, decreased PICs, CCL2, CXCR3, and VCAM-1, adjusted TH, GAD67, and GABA in PVN and plasma NE. However, when we stopped the drug intervention and continued feeding with the high-salt diet for a month, we observed that HS + MCC950' group had significant activation of ASC, IL-1 $\beta$, increased VCAM-1, CCL2, and CXCR3 expression again in the PVN compared to the control group.

\section{Conclusions}

In summary, our results show that NLRP3 plays a key role in prehypertensive rats induced by high-salt diet, via an inflammatory mechanism that increases IL-1 $\beta$, IL- 6 , and TNF- $\alpha$; chemokine CCL2, CXCR3; adhesion molecule VCAM-1 and adjusts excitatory neurotransmitters and inhibitory neurotransmitters, as shown in Additional file 1: Figure S1. These findings shed new lights into the molecular mechanism that controls hypertension; however, whether NLRP3 could be used as a therapeutic target for hypertension remains to be clarified.

\section{Limitations}

Our study has limitations. We observed that adhesion molecule VCAM-1 and chemokine CCL2, CXCR3 are highly expressed in the PVN; however, it is unclear which cells express these molecules, endothelial cells, glial cells or infiltrating leukocytes? Then, what activates the NLRP3? What are the first steps that trigger the inflammation response in the PVN? All these questions needs to be further explored and discussed.

\section{Additional file}

Additional file 1: Figure S1. Salt-induced prehypertension is partly due to the role of NLRP3 in PVN, via an inflammatory mechanism. Blockade of brain NLRP3 attenuates prehypertensive response, possibly via downregulating the cascade reaction triggered by inflammation and restoring the balance of neurotransmitters (PPTX 203 kb)

\section{Abbreviations}

ASC: Adapter protein apoptosis-associated speck like protein; BP: Blood pressure; CCL2: Chemokine ligand 2; CXCR3: C-X-C chemokine receptor type 3; DAMP: Danger-associated molecular pattern; DOCA: Deoxycorticosterone acetate; GABA: Gamma-aminobutyric acid; GAD67: 67-kDa isoform of glutamate decarboxylase; Iba-1: Ionized calcium-binding adaptor 
molecule-1; ICAM-1: Intercellular adhesion molecule 1; LL-18: Interleukin 18; IL13: Interleukin 13; IL-6: Interleukin 6; MAP: Mean arterial pressure; mmHg: Millimeter of mercury; NF-KB: Nuclear factor-kappa B; NLRP3: Nod-like receptor with pyrin domain containing 3; PBMC: Peripheral blood mononuclear cell; PICs: Pro-inflammatory molecules; pro-caspase-1: Pro-cysteine aspartic acid protease-1; PVN: Hypothalamic paraventricular nucleus; SD rats: Sprague-Dawley rats; TH: Tyrosine hydroxylase; TLR4: Toll-like receptor 4 TNF-a: Tumor necrosis factor-a; VCAM-1: Vascular cell adhesion molecule 1

\section{Funding}

This study was supported by National Natural Science Foundation of China (nos.81600333, 81770426), China Postdoctoral Science Foundation (nos. 2016 M602835, 2016 M592802), Shaanxi Postdoctoral Science Foundation (nos. 2016BSHEDZZ91, 2016BSHEDZZ88), and Jiamusi University project (no. JMSUJCMS2016-043). The funders had no role in the study design, data collection and analysis, decision to publish, or preparation of the manuscript.

\section{Availability of data and materials}

Data sharing is not applicable to this article as no datasets were generated or analyzed during the current study.

\section{Authors' contributions}

YK designed the study. MW, XY, QS, XL, KL, LF, YL, and HL performed the data analysis and drafted the manuscript. MW, QS, RS, HT, and HL performed all the experiments and participated in the data analysis. All authors reviewed the manuscript. All authors read and approved the final manuscript.

\section{Ethics approval and consent to participate}

The experimental rules and regulations in accordance with the Nationa Institutes of Health Guide for the Care and Use of Laboratory Animals were duly followed. The approval for our study was obtained from the Xi'an Jiaotong University Committee for Animal Research.

\section{Competing interests}

The authors declare that they have no competing interests.

\section{Publisher's Note}

Springer Nature remains neutral with regard to jurisdictional claims in published maps and institutional affiliations.

\section{Author details}

'Department of Physiology and Pathophysiology, Xi'an Jiaotong University School of Basic Medical Sciences, Key Laboratory of Environment and Genes Related to Diseases (Xi'an Jiaotong University), Ministry of Education, Xi'an 710061, China. ${ }^{2}$ Department of Immunology, School of Basic Medical Sciences, Jiamusi University, Jiamusi 154007, China. ${ }^{3}$ Department of Rehabilitation Medicine, People's Hospital of Baoan District, Shenzhen 518100, China. ${ }^{4}$ Department of Pathology, Xi'an Jiaotong University School of Basic Medical Sciences, Xi'an Jiaotong University Health Science Center, Xi'an 710061, China.

\section{Received: 12 October 2017 Accepted: 15 March 2018}

\section{Published online: 24 March 2018}

\section{References}

1. Pauletto P, Rattazzi M. Inflammation and hypertension: the search for a link. Nephrol Dial Transplant. 2006;21:850-3.

2. Mancia G, Grassi G. The autonomic nervous system and hypertension. Circ Res. 2014:114:1804-14.

3. Sriramula S, Haque M, Majid DS, Francis J. Involvement of tumor necrosis factor-alpha in angiotensin II-mediated effects on salt appetite, hypertension, and cardiac hypertrophy. Hypertension. 2008;51:1345-51.

4. Cardinale JP, Sriramula S, Mariappan N, Agarwal D, Francis J. Angiotensin IIinduced hypertension is modulated by nuclear factor-kappaBin the paraventricular nucleus. Hypertension. 2012;59:113-21.

5. Su Q, Qin DN, Wang FX, Ren J, Li HB, Zhang M, Yang Q, Miao YW, Yu XJ, Qi $J$, et al. Inhibition of reactive oxygen species in hypothalamic paraventricular nucleus attenuates the renin-angiotensin system and proinflammatory cytokines in hypertension. Toxicol Appl Pharmacol. 2014;276:115-20.

6. Dange RB, Agarwal D, Masson GS, Vila J, Wilson B, Nair A, Francis J. Central blockade of TLR4 improves cardiac function and attenuates myocardial inflammation in angiotensin II-induced hypertension. Cardiovasc Res. 2014; 103:17-27.

7. Dange RB, Agarwal D, Teruyama R, Francis J. Toll-like receptor 4 inhibition within the paraventricular nucleus attenuates blood pressure and inflammatory response in a genetic model of hypertension. J Neuroinflammation. 2015:12:31.

8. Cassel SL, Joly S, Sutterwala FS. The NLRP3 inflammasome: a sensor of immune danger signals. Semin Immunol. 2009;21:194-8.

9. Yu Y, Qin J, Chen D, Wang H, Wang J, Yu Y. Chronic cardiovascular diseaseassociated gene network analysis in human umbilical vein endothelial cells exposed to 2,3,7,8-tetrachlorodibenzo-p-dioxin. Cardiovasc Toxicol. 2015;15:157-71.

10. Janahmadi Z, Nekooeian AA, Moaref AR, Emamghoreishi M. Oleuropein offers cardioprotection in rats with acute myocardial infarction. Cardiovasc Toxicol. 2015;15:61-8.

11. Kang YM, Ma Y, Zheng JP, Elks C, Sriramula S, Yang ZM, Francis J. Brain nuclear factor-kappa B activation contributes to neurohumoral excitation in angiotensin Il-induced hypertension. Cardiovasc Res. 2009:82:503-12.

12. Qi J, Zhao XF, Yu XJ, Yi QY, Shi XL, Tan H, Fan XY, Gao HL, Yue LY, Feng ZP, Kang YM. Targeting interleukin-1 beta to suppress sympathoexcitation in hypothalamic paraventricular nucleus in Dahl salt-sensitive hypertensive rats. Cardiovasc Toxicol. 2016;16:298-306.

13. Nguyen KT, Deak T, Will MJ, Hansen MK, Hunsaker BN, Fleshner M, Watkins LR, Maier SF. Timecourse and corticosterone sensitivity of the brain, pituitary, and serum interleukin-1 beta protein response to acute stress. Brain Res. 2000;859:193-201.

14. Kang YM, Zhang AQ, Zhao XF, Cardinale JP, Elks C, Cao XM, Zhang ZW, Francis J. Paraventricular nucleus corticotrophin releasing hormone contributes to sympathoexcitation via interaction with neurotransmitters in heart failure. Basic Res Cardiol. 2011;106:473-83.

15. Moller K, Posel C, Kranz A, Schulz I, Scheibe J, Didwischus N, Boltze J, Weise G, Wagner DC. Arterial hypertension aggravates innate immune responses after experimental stroke. Front Cell Neurosci. 2015:9:461.

16. Ishibashi M, Hiasa K, Zhao Q, Inoue S, Ohtani K, Kitamoto S, Tsuchihashi M, Sugaya T, Charo IF, Kura S, et al. Critical role of monocyte chemoattractant protein-1 receptor CCR2 on monocytes in hypertension-induced vascular inflammation and remodeling. Circ Res. 2004:94:1203-10.

17. Harwani SC, Chapleau MW, Legge KL, Ballas ZK, Abboud FM. Neurohormonal modulation of the innate immune system is proinflammatory in the prehypertensive spontaneously hypertensive rat, a genetic model of essential hypertension. Circ Res. 2012;111:1190-7.

18. Ganta CK, Lu N, Helwig BG, Blecha F, Ganta RR, Zheng L, Ross CR, Musch TI, Fels RJ, Kenney MJ. Central angiotensin II-enhanced splenic cytokine gene expression is mediated by the sympathetic nervous system. Am J Physiol Heart Circ Physiol. 2005;289:H1683-91.

19. Gouw AA, Seewann A, van der Flier WM, Barkhof F, Rozemuller AM Scheltens P, Geurts JJ. Heterogeneity of small vessel disease: a systematic review of MRI and histopathology correlations. J Neurol Neurosurg Psychiatry. 2011;82:126-35

20. Kaiser D, Weise G, Moller K, Scheibe J, Posel C, Baasch S, Gawlitza M, Lobsien D, Diederich K, Minnerup J, et al. Spontaneous white matter damage, cognitive decline and neuroinflammation in middle-aged hypertensive rats: an animal model of early-stage cerebral small vessel disease. Acta Neuropathol Commun. 2014:2:169.

21. Pasceri V, Willerson JT, Yeh ET. Direct proinflammatory effect of C-reactive protein on human endothelial cells. Circulation. 2000:102:2165-8.

22. Ling YH, Krishnan SM, Chan CT, Diep H, Ferens D, Chin-Dusting J, KempHarper BK, Samuel CS, Hewitson TD, Latz E, et al. Anakinra reduces blood pressure and renal fibrosis in one kidney/DOCA/salt-induced hypertension. Pharmacol Res. 2016;116:77-86.

23. van Weering HR, Boddeke HW, Vinet J, Brouwer $\mathrm{N}$, de Haas AH, van Rooijen N, Thomsen AR, Biber KP. CXCL10/CXCR3 signaling in glia cells differentially affects NMDA-induced cell death in CA and DG neurons of the mouse hippocampus. Hippocampus. 2011;21:220-32.

24. Hofer MJ, Carter SL, Muller M, Campbell IL. Unaltered neurological disease and mortality in CXCR3-deficient mice infected intracranially with lymphocytic choriomeningitis virus-Armstrong. Viral Immunol. 2008;21:425-33.

25. Muller M, Carter SL, Hofer MJ, Manders P, Getts DR, Getts MT, Dreykluft A, Lu B, Gerard C, King NJ, Campbell IL. CXCR3 signaling reduces the severity of experimental autoimmune encephalomyelitis by controlling the parenchymal distribution of effector and regulatory $T$ cells in the centra nervous system. J Immunol. 2007;179:2774-86. 
26. Youn JC, Yu HT, Lim BJ, Koh MJ, Lee J, Chang DY, Choi YS, Lee SH, Kang SM, Jang $Y$, et al. Immunosenescent CD8+ T cells and C-X-C chemokine receptor type 3 chemokines are increased in human hypertension. Hypertension. 2013;62:126-33.

27. Coll RC, Robertson AA, Chae JJ, Higgins SC, Munoz-Planillo R, Inserra MC, Vetter I, Dungan LS, Monks BG, Stutz A, et al. A small-molecule inhibitor of the NLRP3 inflammasome for the treatment of inflammatory diseases. Nat Med. 2015;21:248-55.

28. Mridha AR, Wree A, Robertson AA, Yeh MM, Johnson CD, Van Rooyen DM, Haczeyni F, Teoh NC, Savard C, loannou GN, et al. NLRP3 inflammasome blockade reduces liver inflammation and fibrosis in experimental NASH in mice. J Hepatol 2017;66:1037-46.

29. Li HB, Qin DN, Suo YP, Guo J, Su Q, Miao YW, Sun WY, Yi QY, Cui W, Cheng $\mathrm{K}$, et al. Blockade of salusin-beta in hypothalamic paraventricular nucleus attenuates hypertension and cardiac hypertrophy in salt-induced hypertensive rats. J Cardiovasc Pharmacol. 2015;66:323-31.

30. Li HB, Qin DN, Ma L, Miao YW, Zhang DM, Lu Y, Song XA, Zhu GQ, Kang YM. Chronic infusion of lisinopril into hypothalamic paraventricular nucleus modulates cytokines and attenuates oxidative stress in rostral ventrolateral medulla in hypertension. Toxicol Appl Pharmacol. 2014;279:141-9.

31. Kang YM, Zhang DM, Yu XJ, Yang Q, Qi J, Su Q, Suo YP, Yue LY, Zhu GQ Qin DN. Chronic infusion of enalaprilat into hypothalamic paraventricular nucleus attenuates angiotensin II-induced hypertension and cardiac hypertrophy by restoring neurotransmitters and cytokines. Toxicol Appl Pharmacol. 2014;274:436-44.

32. Sumbria RK, Grigoryan MM, Vasilevko V, Krasieva TB, Scadeng M, Dvornikova AK, Paganini-Hill A, Kim R, Cribbs DH, Fisher MJ. A murine model of inflammation-induced cerebral microbleeds. J Neuroinflammation. 2016;13:218.

33. MohanKumar SM, MohanKumar PS, Quadri SK. Specificity of interleukin1beta-induced changes in monoamine concentrations in hypothalamic nuclei: blockade by interleukin-1 receptor antagonist. Brain Res Bull. 1998;47:29-34.

34. Kang YM, He RL, Yang LM, Qin DN, Guggilam A, Elks C, Yan N, Guo Z, Francis J. Brain tumour necrosis factor-alpha modulates neurotransmitters in hypothalamic paraventricular nucleus in heart failure. Cardiovasc Res. 2009; 83:737-46.

35. Jander S, Lausberg F, Stoll G. Differential recruitment of CD8+ macrophages during Wallerian degeneration in the peripheral and central nervous system. Brain Pathol. 2001;11:27-38.

36. Jander S, Schroeter M, D'Urso D, Gillen C, Witte OW, Stoll G. Focal ischaemia of the rat brain elicits an unusual inflammatory response: early appearance of CD8+ macrophages/microglia. Eur J Neurosci. 1998;10:680-8.

37. Li HB, Qin DN, Cheng K, Su Q, Miao YW, Guo J, Zhang M, Zhu GQ, Kang YM. Central blockade of salusin beta attenuates hypertension and hypothalamic inflammation in spontaneously hypertensive rats. Sci Rep. 2015;5:11162.

38. Song XA, Jia LL, Cui W, Zhang M, Chen W, Yuan ZY, Guo J, Li HH, Zhu GQ, Liu H, Kang YM. Inhibition of TNF-alpha in hypothalamic paraventricular nucleus attenuates hypertension and cardiac hypertrophy by inhibiting neurohormonal excitation in spontaneously hypertensive rats. Toxicol Appl Pharmacol. 2014;281:101-8.

39. Harrison DG, Guzik TJ, Lob HE, Madhur MS, Marvar PJ, Thabet SR, Vinh A, Weyand CM. Inflammation, immunity, and hypertension. Hypertension. 2011;57:132-40

40. Agarwal D, Haque M, Sriramula S, Mariappan N, Pariaut R, Francis J. Role of proinflammatory cytokines and redox homeostasis in exercise-induced delayed progression of hypertension in spontaneously hypertensive rats. Hypertension. 2009;54:1393-400.

41. Yu XJ, Zhang DM, Jia LL, Qi J, Song XA, Tan H, Cui W, Chen W, Zhu GQ, Qin DN, Kang YM. Inhibition of NF-kappaB activity in the hypothalamic paraventricular nucleus attenuates hypertension and cardiac hypertrophy by modulating cytokines and attenuating oxidative stress. Toxicol Appl Pharmacol. 2015;284:315-22.

42. Jia LL, Kang YM, Wang FX, Li HB, Zhang Y, Yu XJ, Qi J, Suo YP, Tian ZJ, Zhu $Z$, et al. Exercise training attenuates hypertension and cardiac hypertrophy by modulating neurotransmitters and cytokines in hypothalamic paraventricular nucleus. PLoS One. 2014;9:e85481.

43. Baggiolini M. Chemokines and leukocyte traffic. Nature. 1998;392:565-8.

44. Heidt T, Sager HB, Courties G, Dutta P, Iwamoto Y, Zaltsman A, von Zur MC, Bode C, Fricchione GL, Denninger J, et al. Chronic variable stress activates hematopoietic stem cells. Nat Med. 2014;20:754-8.
45. Gelderblom M, Weymar A, Bernreuther C, Velden J, Arunachalam P, Steinbach K, Orthey E, Arumugam TV, Leypoldt F, Simova O, et al. Neutralization of the IL-17 axis diminishes neutrophil invasion and protects from ischemic stroke. Blood. 2012;120:3793-802.

46. Liao JK. Linking endothelial dysfunction with endothelial cell activation. J Clin Invest. 2013;123:540-1.

47. Ley K, Laudanna C, Cybulsky MI, Nourshargh S. Getting to the site of inflammation: the leukocyte adhesion cascade updated. Nat Rev Immunol. 2007;7:678-89.

48. Krishnan SM, Dowling JK, Ling YH, Diep H, Chan CT, Ferens D, Kett MM, Pinar A, Samuel CS, Vinh A, et al. Inflammasome activity is essential for one kidney/deoxycorticosterone acetate/salt-induced hypertension in mice. $\mathrm{Br} J$ Pharmacol. 2016;173:752-65.

\section{Submit your next manuscript to BioMed Central and we will help you at every step:}

- We accept pre-submission inquiries

- Our selector tool helps you to find the most relevant journal

- We provide round the clock customer support

- Convenient online submission

- Thorough peer review

- Inclusion in PubMed and all major indexing services

- Maximum visibility for your research

Submit your manuscript at www.biomedcentral.com/submit
Biomed Central 